\title{
Cuatro casos de etimología poética en Heródoto: Los nomina loquentia de Bato, Crío, Demarato y Cípselo ${ }^{1}$
}

\section{Four Cases of Poetic Etymology in Herodotus: The Nomina loquentia of Battus, Crius, Demaratus and Cypselus}

\author{
Bernardo BERRUECOS FRANK \\ https://orcid.org/0000-0002-7486-5395 \\ Instituto de Investigaciones Filológicas, Universidad Nacional Autónoma de México, México \\ bernardoberruecos@gmail.com
}

RESUMEN: Este estudio intentará demostrar cómo, a lo largo de las Historias de Heródoto, los nombres propios tienen una función narrativa importante y constituyen no sólo un recurso prominente del arte literario del autor, sino también de su método de concatenación y ordenamiento de la información. Los significados de los nombres funcionan como microrrelatos paralelos al relato en que se insertan y contribuyen a estructurar algunos elementos de la configuración histórica de la narración. Después de algunas reflexiones sobre los inicios de la filología en las Historias y sobre cómo los juegos etimológicos constituyen una prolongación y un complemento de la vocación filológica del historiador, se presentarán cuatro casos de nomina loquentia en los que los nombres funcionan como cápsulas de significación que articulan literariamente ciertos episodios de la narrativa histórica y ayudan a jerarquizar e interpretar las distintas versiones de los acontecimientos.

Palabras Clave: Heródoto, Historias, etimología poética, nomina loquentia; microrrelato

AвstRact: The present study will show how, in Herodotus' account of the Persian wars, proper names have a key narrative function and are also part of his method of historical exposition. Herodotus uses nomina loquentia to insert micro-narratives that affect the processes of meaning-making in the main story and, sometimes, even in the general historical account. After some consider-

\footnotetext{
${ }^{1}$ Investigación realizada gracias al Programa UNAM-PAPIIT <IN401718> "Intertextualidad y alusividad en los géneros poéticos griegos y latinos. Perspectivas formales y pragmáticas para el estudio de los sistemas literarios y sus modelos". 
ations regarding the origins of philology in the Histories and the ways in which etymological wordplay is a prolongation and an addition to the historian's philological activities, four cases of nomina loquentia will be presented in which names function as capsules of meaning that allow the historian to articulate and offer an interpretation of different contrasting narratives of a historical event.

Keywords: Herodotus, Histories, Poetic Etymology, nomina loquentia, Microstory

ReCiBIDO: 27/02/2020 • ACEPTADO: 22/04/2020 • VeRsión FinAL: 24/07/2020

\section{INTRODUCCIÓN}

Para edificar su iotogín, cuyo núcleo está formado por la contraposición entre el mundo griego y el bárbaro, Heródoto no sólo investigó los hechos ( $\tau \grave{\alpha} \gamma \varepsilon v o ́ \mu \varepsilon v \alpha$ ) que propiciaron las guerras Médicas, sino que, como lo dice en su Proemio, procuró esclarecer las causas que ocasionaron los enfren-

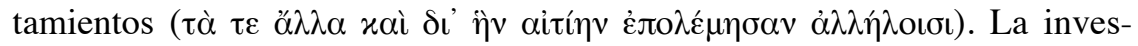
tigación de las causas requirió de un método complejo para compendiar, jerarquizar e interpretar la información recabada en sus indagaciones sobre las diversas culturas que sometió a examen. Este interés por lo bárbaro, esta condición filobárbara de la cual habló Plutarco, ${ }^{2}$ supuso una observación de las lenguas de los pueblos no griegos, que, a la vez, despertó un interés por comparar entre sí los datos lingüísticos recogidos para, así, construir un pensamiento descriptivo y reflexivo sobre la propia lengua griega. Con este poderoso estímulo extranjero, mucho antes de que se constituyera en Alejandría la primera filología propiamente científica, inician las primeras manifestaciones, rudimentarias y primerizas, de la ciencia filológica. ${ }^{3}$

Más allá de todos aquellos pasajes, numerosos por cierto, en los que es posible rastrear preocupaciones genuinamente filológicas en las Historias, ${ }^{4}$




lo, salvo que se indique lo contrario, son las que figuran en el Thesaurus Linguae Graecae. Para el texto de Heródoto se cita la edición de Legrand (Les Belles Lettres).

${ }^{3}$ Véase el estudio clásico de Diels, "Die Anfänge der Philologie bei den Griechen”, 1910, en el que se argumenta con muchos ejemplos cómo Heródoto, junto con Demócrito, son los grandes cofundadores de la ciencia filológica.

${ }^{4}$ Por ejemplo, el relato sobre el experimento lingüístico del rey egipcio Psamético (2.2-3), que tiene como resultado un auténtico rastreo léxico, en particular, según Heródoto, en la lengua frigia; el famoso pasaje sobre las variantes dialectales de la lengua jonia (1.142.8-19); las traducciones del egipcio al griego que, aunque podrían ser en algunos casos meras etimologías populares, delatan un interés por considerar la pluralidad lingüística focalizándola hacia el núcleo semántico de la lengua griega (el nombre egipcio de los desertores en 2.30, el nombre del cocodrilo en 2.69, el nombre griego de la ciudad egipcia de Oasis en 3.26, entre otras), las re- 
hay un recurso que recorre la totalidad de la obra de Heródoto y del cual nos vamos a ocupar aquí que, de algún modo, se deriva y es producto de esta introspección filológica. Se trata del tema de los ỏvó $\mu \alpha \tau \alpha$ y sus significados a lo largo de las Historias.

Como se sabe, la etimología en la poesía épica, por nombrarla en términos anacrónicos, ${ }^{5}$ cumplía una función no meramente incidental y accesoria, sino que en ocasiones llegaba a contribuir de manera poderosa a la construcción de ciertos episodios narrativos y a la caracterización de los personajes. ${ }^{6}$ Desde Homero, el recurso de la etimología poética, es decir, la construcción de tejidos fónicos que articulan la dicción de los poetas y que descubren de forma explícita vínculos semánticos inusitados entre unos nombres y otros, respondía y alimentaba, desde la perspectiva de la audiencia, aquella antigua creencia sobre el poder mágico de los nombres, sobre cómo el significado inscrito en ellos prefigura y determina el destino de sus portadores (nomenomen). Dentro de la historia de las concepciones griegas acerca del lenguaje, el caso de Heródoto resulta peculiar. Por una parte, sus investigaciones manifiestan una postura racionalista que preludia los inicios de la ciencia filológica e introduce en el pensamiento griego el estudio de diversas lenguas y la subsecuente reflexión sobre las raíces comunes que podría haber entre ellas. ${ }^{7}$ Por otra parte, no parece descuidar la función que los nombres y

flexiones sobre el origen egipcio de los nombres de los dioses griegos (2.50), las anotaciones sobre la regularidad de ciertos rasgos morfológicos del persa (1.139 y 1.148), entre muchos otros.

${ }^{5}$ No se debe perder de vista que una "etimología" en la antigüedad no es el producto de una ciencia lingüística definida, sino que más bien está emparentada con las formas que habían desarrollado la poesía y la literatura de jugar con las palabras a través de paronimias, paronomasias y figuras etimológicas. A diferencia de los otros juegos de palabras, la etimología intenta dar una explicación del significado de los nombres y de cuáles son las relaciones de éstos con


aunque en el Fedro, 243a8, en una cita de Estesícoro, y 244a3 y 260e5, encontramos las frases






Top., 35). San Isidoro de Sevilla, además de llamar a las etimologías origenes (véase Quint., 1.6.28, quien ve las etimologías como la actividad quae verborum originem inquirit), también utiliza el sustantivo vis.

${ }^{6}$ Sobre la etimología poética en general, véase Tsitsibakou-Vasalos 2007, introducción y cap. 2. Ejemplos en Homero hay muchos, entre ellos la asociación en $I l$., 10.145 entre 'A $\chi \alpha$ ıьó,

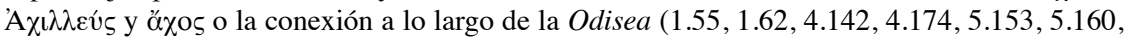


Homero juega también con el nombre de Telémaco. Tenemos algunas figuras etimológicas (hechas por Atenea) sobre el primer componente de su nombre, por ejemplo, en Od., 3.230-231:



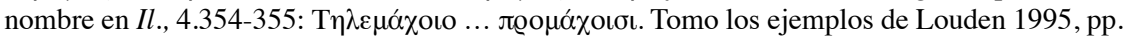
37-39. Vid. Berruecos y Giombini 2019, p. 30, n. 72.

${ }^{7}$ Vid. Diels 1910, p. 19: "Natürlich beruht diese Grundauffassung von der Verwandtschaft der Sprachen nicht auf wissenschaftlichen Einzeluntersuchungen, sondern mehr auf einem nai- 
sus significados podían tener para la estructuración narrativa y poética de su

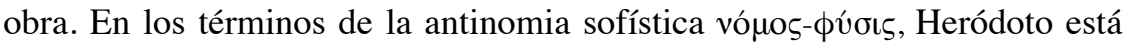
situado en una posición liminar, entre la racionalidad arcaica y la creciente lógica ilustrada, pues inaugura, por un lado, un método de estudio basado en el conocimiento plural y diverso ( $v$ ó $\mu \omega$ ) de otras lenguas y culturas, pero no renuncia, por el otro, al efecto artístico de usar narrativamente los nombres de sus personajes como si estos tuvieran un significado natural e intrínseco



Para acceder a la concepción herodotea sobre el lenguaje y al uso artístico que hace de él, es necesario atender no sólo a los lugares en que Heródoto habla sobre el lenguaje de manera explícita, sino también a los mecanismos implícitos en que el uso del lenguaje revela una función determinada de él. La articulación paradigmática de esta concepción tácita sobre el lenguaje se despliega en lo que hemos denominado aquí la etimología poética de los nombres parlantes herodoteos. ${ }^{8}$ La estructura temática y los acontecimientos de algunos episodios de las Historias descansan en la significación de los nombres de los personajes que intervienen en ellas, con lo cual Heródoto prolonga y pone en práctica las concepciones tradicionales de la cultura griega sobre la motivación eponímica de los nombres, sobre la determinación que instaura el nombre en el destino de su portador. La etimologización, a su vez, puede declararse expresamente, o bien, puede hacerse de manera implícita mediante aliteraciones, paronomasias o juegos de palabras, o por medio de asociaciones semánticas que articulan los episodios en que un personaje actúa y se desarrolla. En este artículo analizaremos algunos casos en los que podemos encontrar etimologizaciones explícitas de los nombres propios, es decir, declaraciones expresas sobre el significado de una serie de apelativos. ${ }^{9}$

ven Sprachgefühl, dem auch die durch Hekataios und Heraklit vertretene Auffassung von dem natürlichen Ursprung der Sprache und darum von der gemeinsamen Wurzel aller menschlichen Rede entsprungen ist".

${ }^{8}$ Tomo el término de "etimología poética" de Tsitsibakou-Vasalos 2007, p. 6: "Ancient etymology thus aims primarily at integrating words, myths, persons and things in a meaningful manner, and provides an internal justification for their presence and function in the poetic canvas". T. Todorov, en su influyente ensayo "Meaning in Literature: A survey" (1971, p. 10) atribuye a R. Jakobson la introducción del término "etimología poética" (véase Jakobson 1987, cap. 6, p. 86). El tema del significado de los nombres ha sido tratado con tal intensidad en los estudios de lingüística, antropología y teoría literaria que tan sólo el estado de la cuestión excedería los propósitos y objetivos de este estudio. Véase, por poner un ejemplo, el tratamiento de R. Barthes sobre los nombres de Proust (1972). En el ámbito de los estudios sobre poesía griega son muy importantes las contribuciones a este respecto de J. Peradotto (1990), C. Calame (2000, cap. 7) y G. Nagy (1979, passim), entre otros.

${ }^{9}$ Seguiremos de cerca los finos análisis realizados en el capítulo 3.3.1 de Campos Daroca 1992, pp. 122-136, titulado "Nombres parlantes en Heródoto". Intentaremos desarrollar con mayor detalle algunos de sus ejemplos, agregar otros no tratados por él (como el de Cípselo) 


\section{BATO: El HIJO BASTARDO-REY Y EL TARTAMUDO COLONIZADOR}

En el libro IV de sus Historias, Heródoto se dispone a narrar la expedición militar persa contra Libia, pero antes relata la colonización de la isla de Tera, antes llamada Caliste, llevada a cabo por un tal Teras, gracias al cual la isla recibió su nombre. Teras tenía un hijo del cual se nos comenta esto: "El niño dijo que no navegaría con él, razón por la cual [su padre] le dijo que lo iba a abandonar como a una oveja entre lobos (öiv èv $\lambda u ́ x o t \sigma \iota)$; a partir de este dicho le vino al joven el nombre de É́lico (Oiónuxos), y casualmente este nombre se impuso" (4.149.1). ${ }^{10}$

Tenemos aquí una clara etimología-etiología del nombre de Eólico que lo hace derivarse del dicho, por lo demás, bíblicamente famoso, ${ }^{11}$ que el padre pronunció al haberse negado su hijo a embarcarse con él a la isla de Tera. Según esto, Eólico significaría algo así como "el oveja-lobo" y su portador llevaría este nombre como inscripción de la negativa que dirigió a su padre. ${ }^{12}$

Un poco más adelante Heródoto prosigue con su narración y nos habla de Bato, uno de los habitantes de la isla de Tera que, según los propios tereos, acompañó a Grino, rey de Tera, a Delfos para consultar al oráculo, el cual le dijo que debía fundar una ciudad en Libia. Siendo muy viejo ya para semejantes encargos, el rey Grino sugirió a la Pitia que encomendara a alguien más la fundación de esa ciudad, teniendo en mente a su compañero Bato. Los tereos no se atrevieron a cumplir el designio oracular, ya que no sabían en dónde se hallaba Libia, razón por la cual sufrieron una terrible sequía que acabó por hacer languidecer, con excepción de uno, todos los árboles de la isla. Es en este contexto que Heródoto nos explica la historia de Frónima, la madre de Bato, mujer cretense que, por una serie de acontecimientos, terminó llegando a Tera en donde un tal Polimnesto la hizo su concubina:

Transcurrido un tiempo nació un niño de habla balbuciente y tartamudo (iøðó-


cireneos dicen, aunque a mi modo de ver se le puso algún otro nombre que fue

\footnotetext{
y enfatizar la función que tienen para las Historias los nomina loquentia de Heródoto no sólo en el nivel artístico y literario, sino también en el propiamente histórico, es decir en lo que concierne a la recopilación de la información, su jerarquización e interpretación. Consideramos que estas tensiones entre la conformación legendaria y mítica de la historia y la construcción histórica de la leyenda se demuestran con claridad en el uso herodoteo de los nombres propios.

${ }^{10}$ Todas las traducciones del griego son propias. El texto griego únicamente figurará cuando se quiera hacer un énfasis en él.

${ }^{11}$ Mateo X. 16.

${ }^{12}$ Según Asheri, Lloyd y Corcella 2007, p. 676, el nombre quizá deba relacionarse más bien con oỉos, con lo cual significaría algo así como "lobo solitario". Sabemos por Pausanias, 3.15.8, de la existencia de un j̣ộov en Esparta dedicado a Eólico.
} 
cambiado al de Bato una vez que llegaron a Libia, y, por provenir del oráculo de Delfos y del honor ahí otorgado, lo obtuvo como sobrenombre. Pues los libios lla-


pitia, al estar profetizando, lo llamó en lengua libia ( $\Lambda$ เ $\beta v x \eta ̣ ~ \gamma \lambda \omega ́ \sigma \sigma \eta)$, a sabiendas



Tenemos aquí reportado el nombre del fundador de Cirene y de la dinastía de los batíadas en un contexto lleno de observaciones onomásticas que merecen comentario. Por una parte, Heródoto trae a colación la denominación libia del sustantivo "rey" ( $\beta \alpha \sigma i \lambda \varepsilon v ́ \varsigma)$ que coincide con el nombre del fundador de Cirene; sin embargo, sospecha, al parecer justificadamente, por lo que Píndaro nos hace saber, ${ }^{13}$ que el nombre original de Bato debió ser otro, ya que esta denominación provino del oráculo en que la Pitia délfica vaticinaba su ulterior estatuto regio. Por otra parte, sucede que este hombre, que se convertiría en el primer rey de Cirene, era tartamudo, lo cual

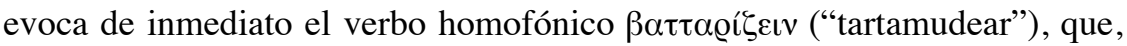
de nuevo, coincide semánticamente con la condición balbuceante de dicho personaje. ${ }^{14} \mathrm{El}$ nombre de Bato no sólo está doblemente motivado, sino que está bilingüemente motivado, con lo cual se pone de relieve la ambigüedad de su significado. Ante la doble motivación, helénica por una parte y libia por la otra, Heródoto se decide por la motivación extranjera, ya que ello le permite dotar de sentido al enigma del oráculo délfico:

Pues una vez que él [sc. Bato] se hizo hombre, fue a Delfos para preguntar sobre su voz, y, tras haberla consultado, la Pitia profetizó esto:


te envía a Libia criadora de ovejas como fundador",

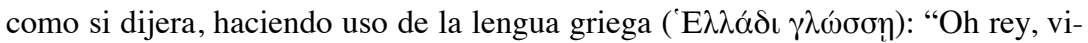
niste por tu voz" (' $\Omega \beta \alpha \sigma i \lambda \varepsilon \hat{v}$, غ̇лì $\phi \omega v \eta े \nu ~ \hat{\eta} \lambda \theta \varepsilon \varsigma)$. Y él respondió esto: "Soberano, yo vine contigo para consultarte sobre mi voz, pero tú me vaticinas otras cosas imposibles, mandándome a Libia para colonizarla; ¿con qué recurso, con qué mano de obra?" Aunque decía esto, no la convenció de dar otra profecía; y como le vaticinaba lo mismo que antes, Bato regresó a Tera, tras abandonarla a la mitad del oráculo (4.155.3-4).

Tenemos aquí la versión cirenaica de la historia que difiere de la versión terea acerca del episodio délfico. En este caso es Bato mismo quien va a

${ }^{13}$ En la Pyth., 5.85 y ss., dedicada a Arcesilao de Cirene, Píndaro dice que el nombre original de Bato fue Aristóteles.

${ }^{14}$ Véase el artículo de Masson 1976, en el que el autor argumenta que con toda probabilidad




Delfos y es a él en persona a quien la Pitia ordena la fundación de Cirene. ${ }^{15}$ Aquí la Pitia se vale de una palabra presuntamente libia para construir su vaticinio, ${ }^{16}$ palabra que se convertiría en el sobrenombre definitivo del fundador de Cirene, cuyo nombre original, como Píndaro declara, era Aristóteles. Bato no sólo lleva en su nombre el defecto de su voz, imperfección que constituye la razón misma por la cual se dirigirá a Delfos, sino que también lleva en su nombre su destino: el tartamudo Aristóteles-Bato devendrá rey, conversión mediada por el cambio de nombre y por el cambio de significado del mismo nombre de la esfera griega a la esfera libia. Batotartamudo, el hijo bastardo de Tera, devendrá Bato-rey, héroe fundador de Cirene. En Libia, paradigma de lo bárbaro e incivilizado, mundo plural ${ }^{17}$ de precariedad lingüística, ${ }^{18}$ en el que nadie se entiende con nadie, en donde reinan las bestias y la desolación desértica se extiende con brutalidad ${ }^{19}{ }^{19}$ sólo ahí es posible que se efectúe semejante transmutación de las posiciones sociales, que el hijo bastardo se convierta en rey y que el tartamudo se vuelva colonizador. ${ }^{20}$ En Libia, el innegable mundo al revés, los valores onomásti-

${ }^{15}$ Cf. Legrand 1960, p. 173, n. I, quien enfatiza la diferencia entre las actitudes de Grino y Bato frente a la Pitia.

${ }^{16} \mathrm{Al}$ respecto de los oráculos en lengua bárbara, en 8.133 Heródoto cuenta cómo el comandante persa Mardonio envió a un cario llamado Mis a consultar diversos oráculos griegos, y cuando llegó al recinto de Apolo Ptoo ocurrió un portento extraordinario (8.135.1): el sacerdote

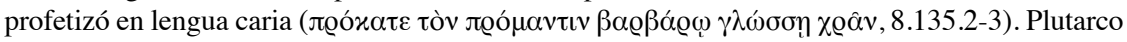
en De def. or., 412a (pasaje lleno de lagunas textuales), hace referencia a este texto herodoteo e interpreta el hecho de que el sacerdote hablase en lengua bárbara como un rechazo por parte del oráculo a dar respuesta a un bárbaro en lengua griega, o a utilizar el griego para ayudar a los bárbaros.

${ }^{17}$ De 4.168 a 4.199 Heródoto menciona las siguientes tribus libias: adirmáquidas, giligamas, asbistas, ausquisas, evesperitas, bácales, nasamones, psilos, garamantes, macas, gindanes, lotófagos, maclies, auseos, amonios, atarantes, atlantes, maxies, záveces y gizantes.

18 Véase 4.183.4 en donde Heródoto dice que los trogloditas tienen una lengua que no se parece a ninguna otra, y que más bien se asemeja a los chillidos de los murciélagos ( $\gamma \lambda \hat{\omega} \sigma \sigma \alpha \nu$



${ }^{19}$ Pasajes en Heródoto que corroboran esta imagen extravagante e inhóspita de Libia son, por ejemplo, 4.168.1, en donde se habla de unas mujeres libias que muerden y escupen los piojos que llevan; 4.180.2 en donde se habla de las doncellas de la tribu de los auseos que luchan entre sí con piedras y garrotes; 4.180 .5 en donde se dice que los hombres de la tribu garamante no se casan con las mujeres y se aparean como bestias; 4.183.2-4 en donde se nos habla de los bueyes que pacen marchando hacia atrás y de los etíopes trogloditas que comen serpientes y otros lagartos; 4.184.4 en donde se dice que los atlantes no sueñan; y, finalmente, 4.191.4 en donde se habla de los animales extraños que habitan Libia: serpientes gigantes, leones, elefantes, osos, seres con cabeza de perro y seres sin cabeza que tienen los ojos en el pecho.

${ }^{20}$ La transmutación cabal del personaje de Bato queda concluida en Paus., 10.15.6-7, en donde leemos que, tras fundar Cirene, Bato se curó de su tartamudeo al aterrorizarse frente a un león con el que se encontró que le hizo emitir un grito tal que su voz quedó rehabilitada. Píndaro, Pyth., 4.61-63, insinúa también cómo convertirse en rey de Cirene le proporcionaría a Bato una cierta cura. 
cos griegos presencian su máximo grado de tergiversación. ${ }^{21}$ Solamente en Libia:

Existen los únicos hombres anónimos que conocemos; como agrupación tienen el nombre de Atarantes, pero para cada uno de ellos no hay ningún nombre (4.184.1).





\section{Cleómenes y CRÍO: LoS CUERNOS DEL SEÑOR CARNERO Y EL INGENIO LINGÜÍSTICO LACÓNICO}

En el contexto de la primera expedición persa contra Grecia relatada en el libro sexto, una vez que los persas, comandados por el general Mardonio, cruzan el Helesponto con el objetivo de llegar a Eretria y a Atenas, tras fracasar y retirar sus tropas, debido a la pérdida sufrida por un par de ataques en su contra bastante exitosos, Darío decide averiguar mediante sus heraldos si los griegos lucharían o se someterían a su poder. Los eginetas, entre otros, decidieron otorgarle a Darío "la tierra y el agua", razón por la cual los atenienses fueron a Esparta para acusarlos por traición y filomedismo. Cleómenes, rey de los espartanos, se dirigió a Egina para arrestar a los implicados en la situación. Ahí se encontró con un egineta de nombre Crío, que se le opuso fervorosamente, acusándolo de estar cometiendo una ilegalidad al no presentarse a Egina junto con el otro rey de Esparta Demarato.

Tras haber sido expulsado de Egina, Cleómenes le preguntó a Crío (Koı̀̀v) que

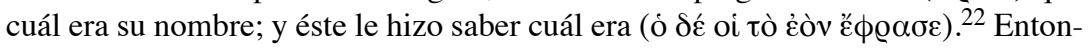
ces Cleómenes le dijo: "Ahora mismo, carnero ( $\chi \varrho \iota \varepsilon ́)$, cubre de bronce tus cuernos ( $x \varepsilon ́ \varrho \varepsilon \alpha)$, ya que habrás de encontrarte con una gran desgracia” (6.50.3).

Como vemos, Heródoto juega aquí con el nombre Koıós, que significa "carnero". ${ }^{23}$ Cleómenes dirige esta especie de maldición a Crío, acto que

${ }^{21}$ Campos Daroca 1992, p. 128: "En el lenguaje extraño de los habitantes de Libia, un mundo marcado por fuertes insuficiencias lingüísticas, el 'tartamudo' es 'rey'”.

${ }^{22}$ Woodbury 1958, pp. 155-156, discute el sentido del participio tò ċòv en esta frase herodotea: "We are likely to translate: 'he told him what it was'. But it would be better to turn tò ćòv as 'his true name', and better still as 'his real name': that is not simply the name which men give to him, but the name by which the real man is truly known- that in which his reality is expressed". El autor da como ejemplos (n. 34) tres pasajes de las Historias $(1.95 .1,1.116 .5$ y 7.143.1) en los


palabra verdadera" sino como "la palabra real".

${ }^{23}$ Aristófanes en $N u b ., 1356$, juega de manera muy similar con el mismo nombre Crío. Estrepsíades cuenta a petición del coro cómo empezó el conflicto con su hijo Fidípides. El 
sólo es posible por el conocimiento de su verdadero nombre. A diferencia de Odiseo que logra salir de la cueva del cíclope mediante el artificio de mentir al respecto de su nombre, Crío cae en la trampa de Cleómenes. Unos capítulos más adelante (6.73.2), en efecto, se cumplirá la maldición, ya que, después de haber derrocado del poder a Demarato, se dirige a Egina con Leotíquidas, recién nombrado rey, para vengarse del maltrato que había sufrido en su visita anterior y para tomar como rehenes a diez eginetas, entre ellos Crío, y ponerlos en custodia de los atenienses, rehenes que, por cierto, nunca serán devueltos. ${ }^{24}$ Ésta, pues, será la "gran desgracia" que le había vaticinado Cleómenes al señor Carnero. La motivación zoológica del nombre del egineta le permite a Heródoto formular el imperativo de Cleómenes: "cubre tus cuernos de bronce". La etimología no sólo funciona como táctica humorística para hacer un guiño al lector, sino que también transparenta la convicción, presente ya en Homero, de que en ciertas circunstancias la articulación del nombre verdadero puede acarrear consecuencias ominosas. Por otra parte, en el nombre mismo de Crío resuenan una serie de conexiones con la tradición poética que debieron evocar en el auditorio algunas referencias precisas. Sabemos por Hesíodo que Crío era el nombre de uno de los titanes que participaron en la guerra contra Urano y que, posteriormente, fueron encarcelados por Zeus, con ayuda de los hecatónquiros, en las profundidades del Tártaro. ${ }^{25}$ Además, sabemos que Crío se unió a la póntide Euribia para dar a luz a tres hijos: Astreo, Palante y Perses, este último importante por ser padre de la diosa ctónica Hécate. ${ }^{26}$ En lo que respecta a la figura del carnero, ésta parece haber sido asociada, no exclusiva pero sí mayoritariamente, al dios Hermes, tanto en el arte como en los ritos religiosos, de tal forma que en la antigüedad había santuarios dedicados al culto de Hermes Koı́́фo@os ("el conductor del carnero"). ${ }^{27}$ Inclusive sabemos por

padre le pidió al hijo que tomara la lira y cantara un poema de Simónides sobre cómo Crío fue trasquilado, a lo cual Fidípides se negó. Los escolios a este pasaje explican que hace referencia al "Comienzo de una oda dedicada a Crío el egineta: El carnero fue trasquilado convenientemente. Parece que la oda fue famosa y sobresaliente" (Escolio R, Holwerda 1977). Otro escolio (E), además de añadir unas palabras más de Simónides, dice que Crío era un luchador egineta y que el poeta combinó en la frase el significado animal de la palabra con otros significados asociados. Para una discusión de los escolios, véase Molyneux 1992, pp. 47-54.

${ }^{24}$ El hijo de Crío, Polícrito, más adelante (8.92.1-2) se distinguirá en la batalla de Salamina y le reprochará a Temístocles haber acusado a los eginetas de filomedismo. Immerwahr 1966, p. 228, n. 110, comenta este pasaje diciendo que es el símbolo de cómo los eginetas cambiaron "from hostility to peaceful competition".

${ }^{25}$ Véase Hes., Th., 32 y ss. Véase el comentario de West 1966, p. 202, en donde discute la ortografía del nombre.

${ }^{26}$ Th., 375-377.

${ }^{27}$ Véase Paus., 9.22.1, en donde se describe un santuario de Hermes Crióforo en la ciudad de Tanagra y se explica el sobrenombre "Crióforo" diciendo que Hermes evitó una epidemia conduciendo un carnero alrededor de la muralla, razón por la cual un escultor de nombre Ca- 
Pausanias que existió un escultor griego, originario precisamente de Egina y justo del s. v, de nombre Onatas, que hizo una escultura de un Hermes crióforo. ${ }^{28}$ Por otra parte, el carnero es un animal de suma relevancia para el episodio mitológico de Frixo y el vellocino de oro. ${ }^{29}$ En suma, el caso del señor Carnero es un buen ejemplo de "etimología poética". El nombre mismo de Crío y la figura del carnero evocan toda esta serie de referentes del imaginario griego, con lo cual el nombre y la explicitación paronímica de su significado incorporan en el episodio y en el personaje herodoteos una clara ornamentación poética que funciona en sí misma como microrrelato sobrentendido y silencioso dentro de la narración. ${ }^{30}$

Pero, ¿por qué el señor Carnero debe recubrir sus cuernos de bronce? ¿Para qué se recubrían de bronce los cuernos de los animales en Grecia? ¿Para qué podían servir los cuernos de carnero en la antigüedad? La respuesta a la segunda pregunta nos la da Homero. En la Odisea (3.421-426) hay una descripción detallada del sacrificio que, por órdenes de Néstor, hicieron sus hijos en honor de Atenea para procurar un buen augurio al viaje de Telémaco a Esparta. Tenemos aquí testimoniada la práctica de recubrir, en este caso de oro, los cuernos del animal que será sacrificado. ${ }^{31}$ Unos versos más adelante (3.432-438) se describe con lujo de detalle el proceso mediante el cual el herrero, para dorar los cuernos, adhiere las capas de oro con un martillo. ${ }^{32}$

Otro pasaje que puede ayudar a responder a la pregunta se encuentra en el libro VII de las Historias en el que, dentro del contexto de la descripción de los contingentes que componen el ejército de Jerjes, leemos la exposición de la indumentaria bélica de una tribu cuyos miembros: "Tenían sobre su cabeza cascos de bronce, y a estos cascos se añadían orejas y cuernos



lamis hizo una estatua de Hermes con un carnero en sus hombros. Sobre esto véase también Farnell 1971,pp. 33-35.

${ }^{28}$ Pausanias 5.27.8 describe la escultura de un Hermes con un casco en la cabeza, vestido con una túnica y una capa llevando un carnero bajo el brazo.

${ }^{29}$ Véase Diod. Sic., 4.47.5, en donde tenemos una racionalización del mito de Frixo, Hele y el vellocino de oro, en la que reporta la teoría de algunos que decían que el $\pi \alpha \iota \delta \alpha \gamma \omega \gamma o ́ \varsigma$ de Frixo se llamaba Crío (carnero). Diodoro señala que fue sacrificado por Eetes quien lo desolló, clavó su piel en el templo de Ares y la recubrió de oro para que los guardianes del templo la vigilaran mejor.

${ }^{30} \mathrm{La}$ idea de que los nombres propios en la literatura griega funcionan como microrrelatos (micro-récit) fue desarrollada por Calame 2000, en particular cap. 7. Tomamos este término de su estudio. Sobre el poder narrativo inserto en el nombre de Aquiles y los motivos asociados a su significación, véase Nagy 1979, cap. 5.

31 Véase Lambert 1993, pp. 293-297.

32 3.432-435. Hainsworth 1993, p. 184, dice que la descripción de dorar los cuernos evidencia una práctica muy antigua y que el poeta de la Odisea no tuvo conocimiento de ella, ya que representa al herrero "in a highly inaccurate maner", utilizando un martillo para colocar las hojas de bronce. 
Vemos que los cuernos de buey podían recubrirse de bronce para así ser añadidos a un casco de guerra. A la luz de estos pasajes, la frase "cubre de bronce tus cuernos" adquiere sentido. Cleómenes aquí estaría advirtiéndole a Crío, en su calidad de carnero, que se prepare para su propio sacrificio, $\mathrm{y}$, en su calidad de hombre, que se busque una armadura lo suficientemente poderosa para defenderse con éxito: ${ }^{33}$ "Recubre tus cuernos de bronce, señor Carnero, es decir, constrúyete un buen casco y afronta tus desgracias venideras".

En cuanto a la tercera pregunta, la respuesta podría dárnosla un acertijo plasmado en un dístico elegíaco de la Anthologia Graeca:

Un carnero tengo como padre, por él una tortuga me dio a luz;

al nacer maté a mis padres, a ambos (XIV.30).

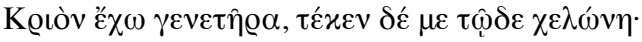

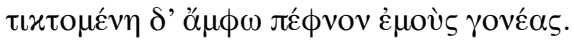

Se ha discutido sobre la solución a esta adivinanza. ${ }^{34}$ Lo más probable es que la respuesta sea la lira, ya que, como se sabe por el Himno homérico a Hermes, las liras se hacían con un caparazón de tortuga. ${ }^{35}$ Además, los griegos llamaban xéoas a los brazos de las liras. Así, los padres de la lira serían el carnero y la tortuga y su muerte posibilitaría la construcción del instrumento. ${ }^{36}$ Vemos, pues, que los cuernos de carnero podían servir también para construir una lira. ${ }^{37}$

${ }^{33}$ Véase Dewald 2006, pp. 145-164, n. 15, quien ve en este pasaje un elemento humorístico que marca algunas características del éthnos espartano, cuyos personajes tienden a ser ingeniosos y, por supuesto, lacónicos en sus expresiones. Lo mismo sugiere Schrader 1981, p. 278 , n. 243: "cuando iban a ser sacrificados, a los carneros los llevaban engalanados".

${ }^{34}$ Véase McCartney 1922, p. 165, quien propone que la solución al acertijo es la $\chi \varepsilon \lambda \omega ́ v \eta$ xoıфóoos, la latina testudo arietaria; véase también Diod. Sic., 12.28, en donde se dice que Pericles fue el primero en construir máquinas para sitiar ciudades, las cuales "son llamadas 'carneros' y 'tortugas'”. El traductor de la Anthologia Graeca de Loeb, W. R. Paton, no supo dar ninguna solución al acertijo ("the answer has not been guessed").

35 Véase HMerc., 25, especialmente 41-42 y 47-51.

${ }^{36}$ Véase Carrington 1961, p. 22: "The simplest answer to the riddle seems to be $\lambda \dot{\varrho} \varrho \alpha$, a lyre, which is defined by Liddell and Scott as 'a stringed instrument with a sounding-board formed

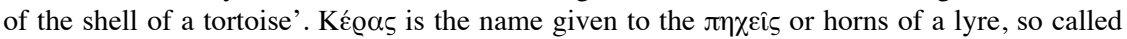


required ram's horns and tortoise-shell and these were not easily acquired without the death of the creatures which owned them".

${ }^{37}$ Otro uso posible que eventualmente se le podía dar a los cuernos de carnero era hacer de ellos una copa ritual utilizada para libaciones a la que los griegos llamaban @́vtóv. Véanse, entre otros pasajes, Soph., Fragmento 772 (Radt), transmitido por una obra de Demetrio Lacón preservada fragmentariamente en el Papiro de Herculano 1012, col. 21,2, en donde leemos: tó $\theta$ '

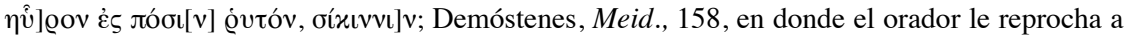


La aliteración ka-kou-kri-ker-ka-ko en la lengua ingeniosa de Cleómenes, finalmente, amplifica la broma imitando onomatopéyicamente el sonido emitido por el carnero y focalizando fónicamente los juegos paronomásticos implicados. ${ }^{38}$

Hay otros pasajes en las Historias que ponen en evidencia, asimismo, el ingenio discursivo de Cleómenes. ${ }^{39}$ Por ejemplo en el libro 5, una vez que los Alcmeónidas hubieron solicitado a los espartanos su ayuda para derrocar al tirano pisistrátida Hipias, habiendo sobornado al oráculo para que siempre prescribiera a los espartanos liberar Atenas, Cleómenes fue a dicha pólis y ayudó al derrocamiento del tirano. De inmediato lucharon por el control de la ciudad Clístenes e Iságoras, este último apoyado por Cleómenes quien se apoderó de la Acrópolis. Ahí el espartano se dirigió al santuario de la diosa y la sacerdotisa le dijo: "Extranjero lacedemonio, retrocede y no entres al santuario, pues no está permitido a los dorios adentrarse aquî" (5.72.3). A lo cual el espartano contestó de manera irreverente: "Pero mujer, no soy dorio

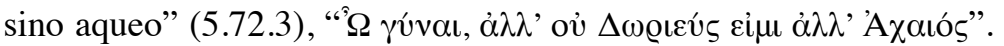

La frase se explica a partir de aquel pasaje (6.53) en que Heródoto señala que los reyes espartanos remontaban su linaje, a través de Heracles, a Perseo, quien era aqueo. Además, el medio hermano de Cleómenes se llamaba Dorieo, con lo cual aquí también engalana su respuesta con ingenio y humor. ${ }^{40}$ Pero Heródoto añade enseguida: "Y él, por no dar crédito al presagio ( $(\lambda \eta \delta \delta$ óv), lo intentó y en seguida fue expulsado junto con los lacedemonios" (5.72.4).

Heródoto califica la advertencia de la sacerdotisa como un $x \lambda \eta \delta \omega ́ v$, es decir, un presagio o augurio que se halla contenido en un nombre o frase y que deviene ominosamente significativo en los acontecimientos del futuro. ${ }^{41}$

Midias que vaya presumiendo por el ágora nombrando diversos tipos de copas, entre ellas, las rhyta; y finalmente Nono de Panópolis, Dionisíacas, 12.360-363, en donde, dentro del contexto de los festejos de los sátiros por la transformación de Ámpelo en vid, el poeta egipcio narra cómo, cuando aún no existían las copas, los sátiros se servían el vino en cuernos de buey.






à retrouver la racine de xદ́gas. Le mot ferait ainsi penser au nom d'autres animaux cornus: lat. ceruos (*kerw-), germ., v. norr. hreinn, anglo-sax. hrān (i.-e. *kroino-) 'renne'”.

${ }^{39}$ Véase Hart 1982, p. 136: "No account of Cleomenes would be complete without some mention of his ready tongue".

${ }^{40}$ En 5.42 Heródoto contrasta fuertemente a Cleómenes con su hermano Dorieo. Mientras Cleómenes no se caracterizaba por su sensatez y de hecho era un tanto maniático (oủ ф@evịฺ́


tiva era un hombre de bien ( $\alpha v \delta \varrho \alpha \gamma \alpha \theta i ́ \eta v)$.




540) que, a su vez, es el primer término de composición del nombre de Cleómenes. 
Por no haber prestado la atención que merecía a la admonición, Cleómenes, aquel que forja su $x \lambda \hat{\varepsilon}$ os ("fama") a partir de su $\mu$ ćvos ("fuerza impetuosa"), aquel que convierte su fuerza ( $\left.\mu \varepsilon \dot{v} v_{\varsigma}\right)$ en fama $(x \lambda \varepsilon 0 \varsigma),{ }^{42}$ fracasará en la empresa que estaba llevando a cabo en Atenas. ${ }^{43} \mathrm{Al}$ no acatar lo que parecía una simple advertencia y responder a ella de manera irreverente, al ignorar el $x \lambda \eta \delta \omega ́ v$ ateniense, Cleómenes atenta contra su propio $x \lambda \dot{\varepsilon}$ os espartano fraguándose un futuro aciago que terminará con su propio suicidio. ${ }^{44}$ Como la proscripción de la sacerdotisa, los ỏvó $\mu \alpha \tau \alpha$, en tanto microrrelatos significativos, son $x \lambda \eta \delta o ́ v \varepsilon \varsigma$, epígrafes determinantes que prescriben el futuro y condicionan el destino de sus portadores.

\section{Demarato: La PLEgaria y La MALdición Del PUEBLO 45}

Otro ejemplo de etimología poética es el caso del nombre del otro rey espartano que compartió el poder con Cleómenes, Demarato. En su historia también encontramos el motivo de la proclamación expresiva como presagio determinante de lo que ocurrirá en el futuro.

En el libro sexto, dentro de la digresión sobre los acontecimientos políticos de Esparta suscitados por la primera expedición persa contra Grecia, Heródoto pone de manifiesto las discrepancias políticas entre los dos reyes espartanos. Mientras Cleómenes era proclive a apoyar políticas intervencionistas, como por ejemplo la colaboración para imponer a Iságoras como

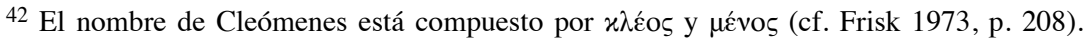
Cleómenes lleva en su nombre las nociones de fama, gloria, ímpetu y fuerza, todas ellas muy apropiadas tanto para su carácter impulsivo y efusivo, como para su papel en la historia que, gracias a Heródoto, no resultó precisamente glorioso, pero sí famoso: "His reign was in many ways controversial, but he had a greater and more enduring influence upon Spartan history than almost any king before or after" (Hart 1982, p. 124).

${ }^{43}$ Cf. Lateiner 2005.

${ }^{44}$ Cleómenes llevará a cabo hasta el final de sus días numerosos actos reprobables: sobornó al oráculo de Delfos para destronar al rey Demarato (6.66.2); intentó organizar una revuelta de los arcadios contra Esparta (6.74), invadió Eleusis (5.74-75) y taló el bosque de Deméter y Perséfone (6.75) e incendió el bosque sagrado de los argivos (6.80). Por todo ello morirá encadenado en Esparta cortándose a jirones la piel con un cuchillo (6.75).

45 Véase el artículo de Boedeker 1987, en el que se analiza minuciosamente el lógos de Demarato esclareciendo los patrones míticos y religiosos que subyacen a él, tales como el mito tindárida, los motivos literarios de Helena y Heracles o el tema de la tíoıs. Asimismo, se examina cómo la historia de Demarato responde a dos modelos narrativos usuales para las historias persas: el del consejero sabio cuyo consejo no es atendido por el gobernante y el del griego exiliado que induce a los persas a atacar a sus conciudadanos. Finalmente, la autora pone de relieve cómo las dos caras de Demarato, la espartana y la persa, tienen similitudes intratextuales, tales como el motivo de la ambivalencia del lenguaje y el motivo que ella llama "dualidad y división", presente este último en tres niveles: $a$ ) entre los reyes de Esparta; $b$ ) entre Esparta y Persia, y $c$ ) entre Esparta y otras ciudades griegas, especialmente Atenas. 
tirano de Atenas o el intento de tomar como rehenes a los eginetas acusados de filomedismo, Demarato apoyaba una política menos interesada en los asuntos internos de otras póleis. Cuando los espartanos y sus aliados invaden el Ática debido a la posibilidad de que Atenas concertara una alianza con los persas (5.74), las tropas de Cleómenes llegan a Eleusis y, justo cuando va a estallar el enfrentamiento, Demarato decide retirarse (5.75),

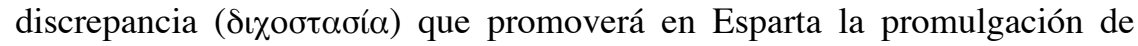
una ley en la cual se establecerá que los dos reyes no podrán acompañar a las tropas (5.75.2) y que una de las dos estatuas de los tindáridas Cástor y Pólux debería permanecer en Esparta. ${ }^{46}$ Asimismo, en el episodio en el que Cleómenes pretende arrestar a los eginetas por filomedismo, Demarato asesora a Crío (6.50.3) para que imposibilite las intenciones del espartano. Y, finalmente, Heródoto dice dos veces (6.51 y 6.61.1) que en Esparta Demarato calumniaba a Cleómenes por envidia y resentimiento. Por todas estas razones, Cleómenes decide urdir un plan para derrocar del poder a Demarato. La conjura se basó en negar que Aristón, su predecesor en el trono, había sido realmente su padre, con lo cual el reinado de Demarato podía proclamarse ilegal.

Cleómenes sabía muy bien los problemas que había tenido Aristón para concebir un hijo. Después de dos matrimonios infructuosos, Aristón se casó por tercera vez, en esta ocasión con la mujer más bella de Esparta (6.61.2), cuyo nombre es omitido en toda la narración, ${ }^{47}$ quien anteriormente estaba casada con otro hombre llamado Ageto. Aristón, tras enamorarse de esta mujer, planeó una treta para quedarse con ella (6.62.1), que consistió en prometerle a Ageto regalarle lo que quisiera a cambio de que éste hiciera lo mismo. Así fue que, tras haberle obsequiado lo que pidió, Aristón le exigió que le diera a cambio a su mujer. Ageto no pudo negarse, pues estaba obligado por los juramentos. Después de casarse con ella, dio a luz a Demarato en menos tiempo de lo normal (6.63.1), razón por la cual Aristón sospechó que el hijo no era suyo. Luego de calcular con los dedos los meses





"No puede ser mío". Los éforos escucharon esto, pero en ese momento no le dieron importancia al asunto. El niño creció y Aristón se arrepentía por lo dicho; pues estaba convencido por completo de que Demarato era su hijo. Y le puso el nombre

\footnotetext{
${ }^{46}$ Cf. Nenci 1994, p. 270.

47 Véase Larson 2006, estudio en que la autora propone que la omisión de ciertos nombres de mujeres a lo largo de las Historias es deliberada y corresponde a una estrategia narrativa según la cual, manteniendo su anonimato, Heródoto les confiere cierto respeto y las exonera de la culpabilidad de los tiranos asociados a ellas; esto se hace de acuerdo con la práctica ateniense de suprimir públicamente los nombres de mujeres respetables.
} 
de Demarato por aquello de que, antes de estos sucesos, los espartiatas en su con-

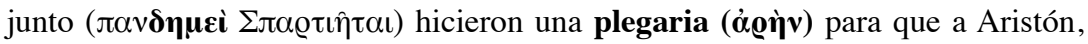
hombre sin duda distinguido entre todos los reyes habidos en Esparta, le naciera

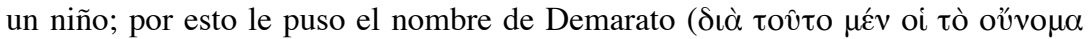

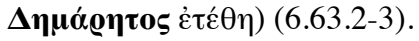

La articulación en voz alta que desmiente la legitimidad de Demarato como heredero del trono será la condición de posibilidad para que, varios años después, Cleómenes suscite entre los espartanos la misma duda. La frase "no puede ser mío" constituye en sí misma el vaticinio por el cual será posible en el futuro el derrocamiento y la destitución de Demarato como rey. La aparentemente casual pronunciación de la negativa tendrá consecuencias históricas relevantes. Heródoto exhibe en el decir de sus personajes algunas piezas que después adquirirán continuidad en el rompecabezas de su trama narrativa, lo cual no sólo revela un principio de composición de la historia herodotea, sino que también responde una vez más a la creencia en que el decir y lo implicado en él pueden tener consecuencias ominosas.

Por otra parte, en estas líneas se da una explicación etimológica del nombre de Demarato que se constituye como un clarísimo nomen parlans: la


bido a las ambigüedades semánticas del sustantivo ỏ@ý, que también quiere decir "ruina, maldición", puede adquirir otro significado. ${ }^{48}$

Así, Cleómenes, a sabiendas de que Aristón había pronunciado aquella sentencia en la que le negaba a Demarato su paternidad, instiga a Leotíquidas a presentar una acusación pública haciendo con él el siguiente trato: si acusaba a Demarato de ilegitimidad, él mismo se volvería rey y le ayudaría a tomar, ahora sí, represalias contra los eginetas (6.65). Leotíquidas acepta, no sólo por el beneficio político que le aportaría, sino aún más porque Demarato era su enemigo personal (6.65.2), ya que le había robado a su prometida Pércalo. ${ }^{49}$ Como no se ponían de acuerdo sobre qué hacer, los espartiatas deciden dirimir la cuestión preguntando al oráculo de Delfos si Demarato era en verdad hijo de Aristón (6.66.1). Cleómenes soborna al

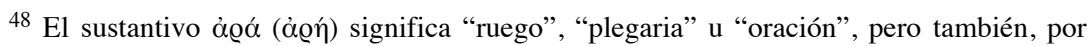
ejemplo en la tragedia, se usa como personificación del deseo de maldición o de venganza. El verbo denominativo ỏoóoual significa "pedir con plegarias" (Il., 1.35-36), o "lanzar imprecaciones contra alguien", esto es, "maldecir" (Soph., OT, 251 o 1291). Véase Liddell-Scott (1996) ad locum, y Chantraine 1980, p. 100. En Homero hay dos nombres muy similares al de Dema-



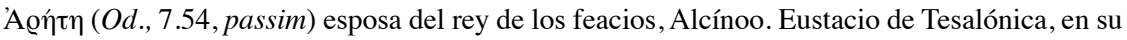
comentario a la Ilíada explica el pasaje de 17.517, en que aparece el nombre de Areto y da su etimología, haciendo referencia al Demarato herodoteo.

49 Boedeker 1987, p. 189, caracteriza este episodio como respuesta al motivo mítico de Helena. 
oráculo para que responda negativamente. Así, Demarato es derrocado y Leotíquidas sube al poder. Y un día cuando:

Se estaban llevando a cabo las Gimnopedias, estando Demarato de espectador, Leotíquidas, siendo ya él mismo rey en lugar de aquél, mandó a su sirviente a preguntarle a Demarato con hilaridad y burla cómo era ser magistrado después de haber sido rey. Y, afligiéndose por la pregunta, le respondió diciendo que él mismo ya había probado ambas cosas, pero aquél no y, además, que esta pregunta sería el principio para los lacedemonios de un infinito mal, o bien, de una infinita felicidad (6.67.2).

De nuevo, la articulación en voz alta, en este caso de una pregunta soberbia e imprudente, condicionará los acontecimientos del futuro. El nombre de Demarato como plegaria del pueblo comienza aquí su conversión semántica. De plegaria pasará a ser maldición, al menos potencialmente. Toda la ambigüedad del significado del nombre se despliega en esta formulación binaria que profetiza la felicidad o la maldad como posibilidades del futuro espartano. ${ }^{50}$ En su calidad de plegaria del pueblo, Demarato fungió como garante de una infinita felicidad para los lacedemonios, felicidad que consistió en haber nacido finalmente tras los intentos infructuosos de su padre para engendrar un heredero; en la misma calidad de plegaria, Demarato seguirá fungiendo en el futuro como garante de esta felicidad al colaborar en la victoria espartana contra los persas, gracias, entre otras cosas, al mensaje encubierto que enviará a Esparta más adelante (7.239). Sin embargo, Demarato deberá vengarse. Y esta tíoı se el motivo literario que activa el otro significado de su nombre. El deseo de venganza por parte de Demarato lo constituye como una maldición para Esparta. En calidad de ruina del pueblo de Esparta, Demarato se convertirá en consejero de Darío y, por lo mismo, podrá cooperar en la derrota griega.

Así pues, Demarato termina en la corte de Darío y de Jerjes en donde es bienvenido como consejero del rey y premiado con tierras (6.70.2). Las ambigüedades de su nombre cobran así pleno sentido, ya que entonces comienza a labrar su destino como maldición del pueblo espartano. Si sus consejos hubiesen sido escuchados por el rey persa, las consecuencias para Esparta hubieran sido catastróficas, pero, para la suerte no sólo de los lacedemonios,

\footnotetext{
${ }^{50}$ Se ha discutido mucho sobre el significado de la frase de Demarato. Para un status quaestionis de las interpretaciones del pasaje, véase el comentario de Nenci 1994, pp. 233-234. En el comentario de How and Wells 1968, p. 90, leemos: "The alternative, not seriously meant, is added for rhetorical contrast". Se suele pensar, con base en un pasaje de Xen., Hell., 6.4.16, y uno de Plut., Ages., 29, que el cargo político que Demarato pudo haber estado ejerciendo, una vez derrocado como rey, era el de éforo, o bien, a partir de Paus., 3.11.2, el de Bıðı๙îs (supervisor de los ejercicios gimnásticos). A partir de esto, Nenci 1994, p. 233, explica el pasaje haciendo énfasis en las tensiones políticas espartanas entre éforos y reyes.
} 
sino de toda Grecia, Jerjes, por desconfianza o simple incredulidad, decide ignorarlo. ${ }^{51}$

Otro ejemplo de cómo Heródoto construye con maestría la ambigüedad inherente al personaje de Demarato, ambigüedad presente en el significado mismo de su nombre, es el episodio del mensaje que envía Demarato a Esparta para anunciar los movimientos del ejército persa. Al final del libro séptimo, después de describir cómo Jerjes degüella el cadáver de Leónidas y ensarta su cabeza en una estaca tras la victoria persa en las Termópilas (7.238), Heródoto se propone retomar el hilo de su narración ${ }^{52}$ para explicar cómo los lacedemonios fueron los primeros en saber que el rey persa se estaba preparando para atacar Grecia. Dice Heródoto:

Se enteraron de una manera extraña. Pues refugiado entre los medos Demarato, el hijo de Aristón, como me parece, y tomo a la verosimilitud como mi aliada, no era benevolente con los lacedemonios, sin embargo, se puede conjeturar si hizo aquello por benevolencia o bien para regodearse. Pues tan pronto como Jerjes decidiera comandar su ejército contra Grecia, estando Demarato en Susa e informándose de aquello, quiso comunicárselo a los lacedemonios. Pero como no podía anunciárselos de otra manera, pues corría el riesgo de ser detectado, ideó lo siguiente: tomó una tablilla doble, raspó su cera y después en la madera de la tablilla escribió las intenciones del rey; habiendo hecho esto de nuevo derritió la cera sobre las letras, a fin de que el portador de la tablilla no tuviera ningún problema frente a los vigilantes de los caminos. Y cuando llegó a Lacedemonia, los lacedemonios no podían interpretarla, hasta que, tal como estoy informado, Gorgo, la hija de Cleómenes y

${ }^{51}$ En dos ocasiones Jerjes desconfía de Demarato y hace caso omiso de sus consejos. En el libro 7, en el contexto de la expedición de Jerjes contra Grecia, el rey persa manda llamar a Demarato, que lo acompañaba en la expedición, y le pregunta si los griegos lucharían contra él ofreciéndole resistencia (7.101). Demarato le contesta que si prefiere escuchar la verdad o solamente que le digan lo que quiere oír. El rey prefiere oír la verdad y he ahí que Demarato, en el nombre de la verdad, hace un elogio a la ỏ@etí griega en general y espartana en particular: los lacedemonios nunca aceptarán la condición de ser esclavizados y lucharán contra los persas inclusive estando el resto de los griegos del lado de Jerjes (7.102). Jerjes responde riendo y despacha a Demarato sin hacerle ningún caso (7.105). Más adelante (7.234-237), Jerjes vuelve a solicitar el consejo de Demarato preguntándole, tras los acontecimientos de las Termópilas, cuántos lacedemonios quedan, cuántos de ellos son guerreros valerosos (7.234) y cuál sería la mejor manera de vencerlos. Demarato contesta que hay una isla de nombre Citera, en la cual los navíos de Jerjes podrían apostarse para generar miedo entre los lacedemonios (7.235). De nuevo, Jerjes, para fortuna de los griegos, decide no hacerle caso, ya que su hermano Aquemenes le hace dudar sobre la confiabilidad del testimonio de Demarato alertándolo de que quizá éste podría ser un traidor a la causa persa (7.236).

${ }^{52}$ El hilo de la narración que aquí se reanuda parece remontarse al capítulo 220, en donde se nos dice que los espartanos habían consultado al oráculo sobre la guerra y la Pitia les había respondido que o Lacedemonia sería destruida por los bárbaros, o que su rey moriría, pero esta consulta tuvo lugar antes de que la amenaza hubiese sido explícita, antes de que la invasión fuese inminente. En este pasaje se explica precisamente por qué los espartanos consultaron al oráculo con tanta antelación. Véase Legrand 1951, pp. 234-235, n. 5. 
mujer de Leónidas, los instruyó, habiéndolo ella misma reflexionado, y les ordenó raspar la cera de modo que ellos encontrarían las letras en la madera. Persuadidos, ellos las encontraron y las leyeron, y entonces las enviaron a los otros griegos. Así, en efecto, se dice que ocurrieron los acontecimientos (7.239). ${ }^{53}$

No queda claro el motivo de la estratagema de Demarato. Como Heródoto lo dice, pudo ser por un cierto impulso de benevolencia para con sus conciudadanos espartanos, o por el regocijo perverso de echarles en cara su inminente desgracia. Sea como sea, la ambigüedad de este acto no sólo responde a y es consecuente con el carácter anfibológico de su propio nombre (Demarato como plegaria y como maldición del pueblo espartano), sino también con la imprecación que había hecho explícita en 6.67.2 sobre el futuro incierto de Esparta: la felicidad o la desgracia. ${ }^{54}$

\section{Cípselo, Labda y Eetión: El vencejo que sonRíe en la colmena, LA COJA Y EL ÁGUILA}

Atenderemos, finalmente, a un pasaje significativo de las Historias en el que se hallan importantes ejemplos de etimología poética. Se trata del episodio en que, dentro del contexto general de la historia de Atenas, tras explicar cómo los atenienses, emancipados de la tiranía (5.78), se habían convertido en una verdadera potencia (5.78) en virtud de su igualdad política y su libertad de expresión (iơro@ín), Heródoto expone cómo los espartanos, frente al poderío ateniense, tramaron restituir en el poder al tirano pisistrátida Hipias, con el objetivo de debilitar a Atenas poniéndola bajo el dominio de la tiranía

53 Este pasaje ha despertado los escrúpulos de los estudiosos, quienes se han decantado o por considerarlo una interpolación, o una adición tardía de Heródoto. How and Wells 1968, pp. 233-234, sospechan, junto con otras autoridades, que este pasaje es una interpolación, no sólo porque no hay una transición al libro 8 , sino más aún porque el lenguaje no parece del todo herodoteo: "It appears highly probable that some part of the text connecting Books VII and VIII was early lost, and into the gap this chapter was thrust by an interpolator". Para un status quaestionis sobre la autenticidad o inautenticidad del pasaje, véase Immerwahr 1966, p. 139, n. 176: "The truth of the matter is that the anecdote is postponed, being shifted from its proper place to the end of the logos in the same manner as the defense of the Alcmaeonids (6.121 f.f., cf. 115)".

54 Demarato sólo aparecerá una vez más en las Historias. En 8.65, acompañado del exiliado ateniense Diceo, presencia un portento sobrenatural que Diceo relaciona con los misterios de Eleusis (una polvareda que avanzaba como si fuera producto de treinta mil hombres en un momento en que el Ática estaba desierta por los ataques persas y que se alzó finalmente al cielo para dirigirse a Salamina), y que interpreta como un presagio de la derrota de Jerjes. Demarato exhorta a Diceo a guardar silencio al respecto, pues peligraban sus vidas si el rey se llegaba a enterar de ello. Sabremos después por Jenofonte (Hell., 3.1.6) que los descendientes de Dema-

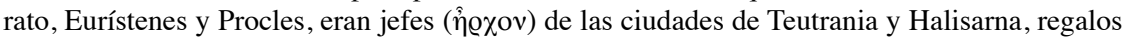
que había recibido su antepasado de parte del rey en agradecimiento por su ayuda. 
(5.91.1). Los espartiatas convocaron a una asamblea con los portavoces de sus aliados (5.91.2) para comunicarles su plan. En ella, el corintio Socles pronunció un largo discurso, ${ }^{55}$ en el que intentó persuadir a los presentes sobre los perjuicios que podía acarrear la tiranía.$^{56}$ En ese pasaje Heródoto inserta la historia sobre la tiranía corintia de los cipsélidas. ${ }^{57}$

No sólo por Heródoto, sino también por Pausanias, ${ }^{58}$ Diodoro Sículo (7.9.4) y Estrabón, ${ }^{59}$ sabemos que Corinto fue gobernada durante muchos años por el régimen oligárquico de los Baquíadas, un clan integrado por numerosas familias ricas y distinguidas. A un hombre llamado Anfión, perteneciente a dicho clan: "Le nació una hija coja; su nombre era Labda. Ya que ninguno de los Baquíadas quería casarse con ella, la desposó Eetión, el hijo de Equécrates, que era del demo de Petra" (5.92.ß.1). El nombre de la niña revela su condición defectuosa. Ella es como la letra lambda, que posee en su grafía una "pierna" más corta que la otra. ${ }^{60}$

Después de un tiempo, al ver Eetión que no le venía ningún hijo de Labda, y preocupado por una eventual esterilidad suya, se dirigió a Delfos para indagar la razón de ello:

Al entrar, la pitia se dirigió a él directamente con estos versos:

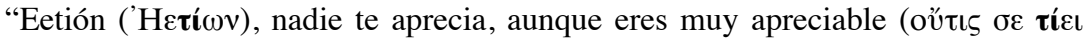

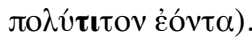

Labda está embarazada y dará a luz a un pedrusco; caerá

sobre los hombres monarcas, hará justicia en Corinto" (5.92.p.2).

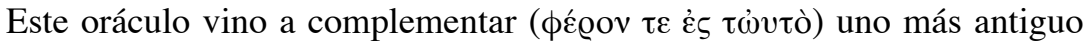
que la Pitia había profetizado a los Baquíadas, ${ }^{61}$ según el cual:

\footnotetext{
${ }^{55}$ El discurso más largo de todas las Historias.

${ }^{56}$ Quizá porque a Corinto le convenía que Atenas fuese independiente como contrapeso a Egina y para mantener su propia libertad (cf. How and Wells 1968, p. 51).

${ }^{57}$ Para el problema de la historicidad del discurso de Socles y de la aparente disonancia entre el contenido de su discurso y la finalidad para la que fue pronunciado, véase Johnson 2001, p. 2. El autor sostiene que Socles, por una parte, "makes use of an oblique storytelling approach that is an ideal method for facing the complex diplomatic situation in which he finds himself"; $y$, por la otra, "reflects what was actually said on the occasion".

58 2.4.4 nos da una genealogía de los reyes de Corinto.

59 8.6.20, en donde nos hace saber que los baquíadas estuvieron en el poder durante doscientos años.

${ }^{60}$ Véase el Etym. Magn., en cuya entrada para $\beta \lambda \alpha \iota \sigma o ́ \varsigma$ ("torcido, distorsionado, pie plano") leemos una alusión a este pasaje herodoteo. Véase Delcourt 1986, pp. 110-111, en donde la autora hace una aproximación, a partir de los nombres, entre Labda y Lábdaco, el abuelo de Edipo, que en su nombre de cojo podría aludir al nombre de Edipo, también relacionado con los pies.

${ }^{61}$ Este procedimiento literario, común por ejemplo al Edipo Rey, es lo que denomina Crahay 1956, p. 239, "les oracles convergents".
} 
"Un águila está preñada entre piedras, dará a luz a un león poderoso y carnicero; de muchos las rodillas paralizará.

Por tanto, consideren bien esto, corintios, que en torno a la bella

Pirene y a la arriscada Corinto habitan".

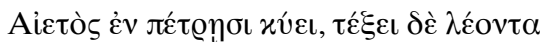

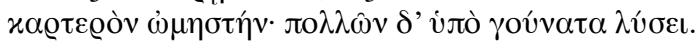

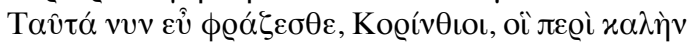

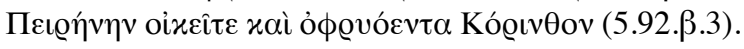

En ambos oráculos tenemos evidentes alusiones etimológicas, o si no, al menos, paronomásticas, que son complementarias entre sí. ${ }^{62}$ En el primero, se etimologiza el nombre de Eetión a partir del verbo tí $\omega$ y del adjetivo

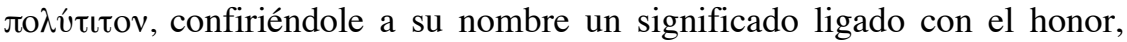
la estima y el aprecio. Además, la introducción del oráculo y sus primeros dos versos saturan en aliteración el fonema " $t$ ", recurso que focaliza los juegos paronomásticos a nivel fónico. En el segundo oráculo, se prolonga la etimologización del nombre de Eetión con la introducción del águila (Eetíon-Aietòs); asimismo, en ambos oráculos se hace alusión al nombre del demo del cual provenía Eetión, Petra, mediante la imagen del pedrusco y del águila preñada entre piedras. ${ }^{63}$

La conjunción de ambos oráculos hace que los Baquíadas decidan dar muerte al hijo de Labda y Eetión. Así, se dirigen a Petra con la determinación de matar al niño. Una vez en su casa, piden ver al niño y:

Cuando, en efecto, Labda lo trajo y se los entregó, por una divina casualidad el niñito sonrió al que entre los hombres lo había tomado, y, habiéndose dado cuenta de esto, una cierta lástima lo contuvo de matarlo, y, compadecido, se lo entregó al segundo, éste al tercero, y así pasó trasladándose a través de todos, de los diez, ninguno queriendo acabar con él. Así, tras devolver el niñito a la madre y salir de la casa, parados frente a la puerta, se reclamaron mutuamente, reprochando sobre todo al que primero lo tomó, ya que no había hecho lo acordado, hasta que, por fin, al cabo de un tiempo, pensaron entrar de nuevo y participar todos en el homicidio (5.92. $\gamma \cdot 3-4)$.

Pero Labda, con una oreja pegada a la puerta, escuchó lo que los Baquíadas se proponían:

Temiendo que ellos cambiaran de opinión y que por segunda vez tomaran al niño e intentaran matarlo, se lo llevó y lo ocultó en donde le parecía que era el lugar más

\footnotetext{
62 Véase Immerwahr 1966, p. 194.

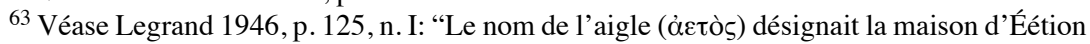

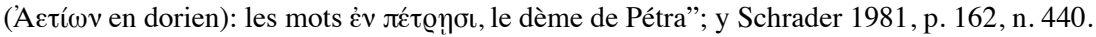


absurdo, en una colmena ( $\boldsymbol{\varkappa} \psi \varepsilon \dot{\lambda} \lambda \eta \boldsymbol{v})$, sabiendo que, si ellos volvían, llegarían a la búsqueda, e irían a rastrear todo. Precisamente esto fue lo que sucedió (5.92.8.1).

Los diez volvieron a entrar, pero por más que buscaron no encontraron al pequeño. "Después de estos acontecimientos, el niño de Eetión iba crecien-

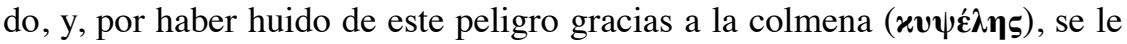

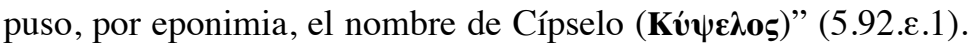

Tenemos aquí la explicitación de la motivación onomástica del nombre del tirano corintio, motivación que ya había sido anunciada prolépticamente un poco antes. ${ }^{64}$ Por haber sido escondido en una colmena (kypséle $)$ recibió el nombre Kýpselos. ${ }^{65}$ Éste es un claro ejemplo de cómo en la narración herodotea algunos antropónimos reciben su explicación a partir de los incidentes de las Historias, de manera que, o bien la estructuración de ciertos episodios se basa en la etimologización de un nombre (el caso de Cípselo), o bien la invención de un nombre estructura el episodio (el caso de Labda). ${ }^{66}$

Es precisamente a partir de este significado apícola del nombre de Cípselo (la colmena) que se puede explicar el epíteto con que el tirano Periandro, su hijo, llamaba a su esposa: Médı ıo $\alpha$ (la abeja) ${ }^{67} \mathrm{La}$ concomitancia de la significación onomástica apícola en Cípselo y Melisa podría ser indicio de que la familia cipsélida algo tenía que ver con el culto a la diosa que Teócri-

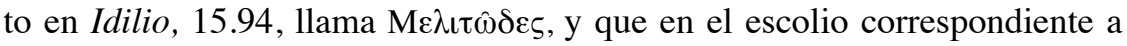
este pasaje se nos explica que se trata de Perséfone. Aunque también, como confirma Hesiquio de Alejandría, podría tratarse más bien de las sacerdo-

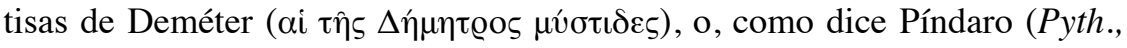

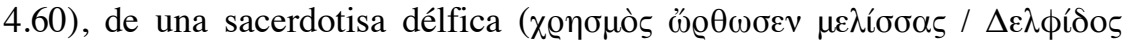

${ }^{64}$ Justo antes de que comience el discurso de Socles y la leyenda de Cípselo, en 5.91.2,

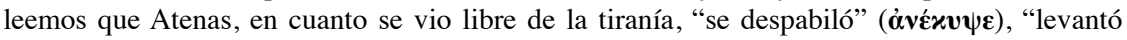

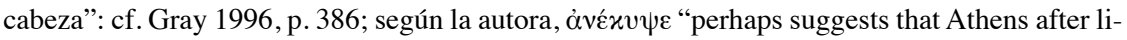

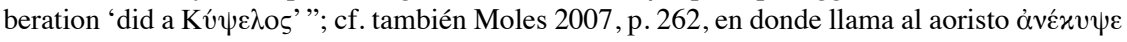
un "witty proleptic pun".

${ }^{65}$ A partir del estudio de Roux 1963, se ha interpretado el sustantivo $x v \psi \varepsilon ́ \lambda \eta$ como "colmena", sentido que se corrobora a partir de un pasaje de Plut., De exil., 601c. Véase también Chantraine 1980, p. 604. El sustantivo se puede interpretar, a partir de un testimonio de Paus. (5.17.5, cf. infra), aproximándolo con el sustantivo $\lambda \alpha ́$ @v $\alpha \xi$ que designaba más bien a un cofre de madera. Pausanias dice explícitamente que los corintios de entonces llamaban a los cofres

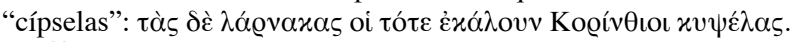

${ }^{66}$ Crahay 1956, p. 238: "Dans notre conte, c'est le nom du héros qui est authentique, et l'étymologie fantaisiste, tandis que d'autres personnages portent des noms parlants, à coup sûr inventés: Labda, la mère du futur tyran". Interpretación contraria a este respecto a la de Delcourt 1986, p. 110: “Aucun des quatre personnages [sc. Lábdaco, Edipo, Labda y Cípselo] n’a de nom. Ils portent uniquement des sobriquets tirés, pour les parents, de leur infirmité, pour les enfants, d'un épisode de leur sauvetage".

${ }^{67}$ Hdt., 5.92.ๆ.2 y 3.258. Sabemos por D. L., 1.94, que el nombre real de Melisa era Líside:

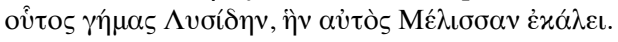




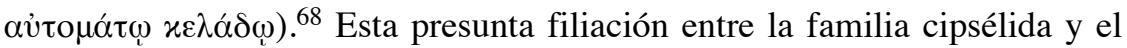
culto a la "abeja délfica" resulta verosímil con los oráculos que la Pitia dio a Cípselo. Así, este nombre posee en su interior una compleja significación que trasluce también el vínculo entre la tiranía corintia y el clero pítico. ${ }^{69}$

La leyenda de Cípselo comparte ciertos rasgos narrativos con la del rey persa Ciro. ${ }^{70} \mathrm{~A}$ ambos intentaron asesinarlos por un oráculo negativo y ambos se salvaron y se volvieron gobernantes. Asimismo, en la leyenda de Cípselo interviene una estructura común con la de Edipo. ${ }^{71}$ Ambos, siendo bebés, evitan la muerte promovida por un oráculo; ambos reciben su nombre a partir del episodio en que estuvieron expuestos a la muerte; ambos, tras volverse adultos, van a Delfos a preguntar sobre su destino. Pero, independientemente de que a muchos estudiosos les haya parecido que la narración de Heródoto es mero folklore ${ }^{72}$ y ficción literaria, lo que aquí nos interesa no es tanto la historicidad del relato, como la estrategia narrativa que él manifiesta, íntimamente ligada al método herodoteo de exposición histórica en el que se explota continuamente el poder etiológico inherente a toda forma de etimologización poética. El episodio completo, incluso, podría haber sido inventado para dar razón del nombre de Cípselo; ${ }^{73}$ así, una vez más, se pone de manifiesto la importancia de los nombres y de su exégesis para la conformación literaria del discurso histórico.

Pero la significación del nombre de Cípselo no se queda aquí. Sabemos por Aristóteles (Hist. an., 618a30) que a un tipo de aves ápodas parecidas a las golondrinas, quizá los vencejos, algunos las llamaban precisamente cíp-

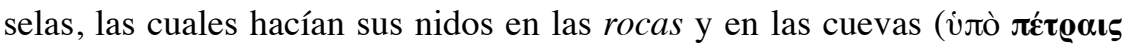

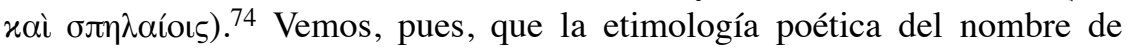
Cípselo se amplía. Si para un griego este nombre podía referirse también a aquellas aves huidizas que anidan en rocas, las referencias oraculares a las piedras adquieren una dimensión significativa aún mayor. Así también (nótese la gracia), el aguila (Eetión) habría dado a su hijo el nombre del ven-

\footnotetext{
${ }^{68}$ Véase Antonelli 1994, pp. 37-42. "È indubbiamente attraente l'ipotesi que esista un qualche legame tra il nome Kú $\psi \varepsilon \lambda_{\circ}$, 'alveare', secondo il significato qui proposto, e l'epiteto

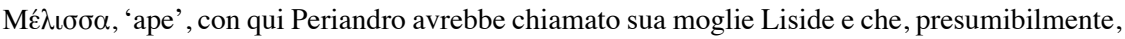
indicava una figura legata all'ambito cultuale. Il presunto rituale, per tanto, potrebbe aver avuto una qualche rilevanza per la famiglia di Cipselo, fin dall'epoca in qui Labda e Eezione diedero al proprio figlio un nome che con il rituale estesso potrebbe forse essere stato in relazione" (p. 41).

${ }^{69}$ Antonelli 1994, p. 37.

70 Véase Immerwahr 1966, p. 194; también Stuart Jones 1894, p. 32.

71 Véase Vernant et Vidal-Naquet $1995^{2}$, pp. 56-62.

${ }^{72}$ Cf. Oost 1972, p. 16; también Crahay 1956, pp. 237-238.

${ }^{73}$ Delcourt 1986, p. 110: "L'histoire est suspecte parce qu'elle pourrait avoir été inventée pour rendre raison du nom de Cypsélos".

${ }^{74}$ Cf. Frisk 1973, II, p. 58.
} 
cejo siguiendo la línea ornitológica de su familia. ${ }^{75}$ Además, este hombrepájaro formaría parte de otros "hombres pájaro" de la tradición literaria y mitológica ${ }^{76}$ como por ejemplo Ícaro, cuyo padre Dédalo, como sabemos, hizo de $\mathrm{cera}^{77}$ las plumas con las que volarían para escapar de Creta, y es precisamente la cera que sale de los oídos, el cerumen, otro de los significados a los que alude el nombre de Cípselo. ${ }^{78}$ Inclusive la frase $x v \psi \varepsilon ́ \lambda \eta v ~ \varepsilon \dot{v}$

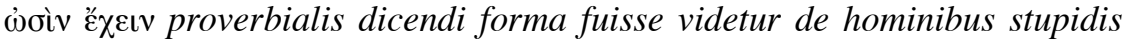
bardisque. ${ }^{79}$ Todos estos estratos de alusiones mitológicas, literarias, históricas y culturales conviven en el interior mismo del nombre de Cípselo: el microrrelato onomástico inscrito en su nombre resuena en los oídos del auditorio y enriquece el relato de Heródoto.

La etimologización a posteriori del nombre de Cípselo y los modelos literarios paradigmáticos de Ciro y Edipo, le permiten a Heródoto construir la leyenda de su milagrosa salvación. Pero la etimologización no se quedó en mera etimologización. Años más tarde, los testimonios de algunos escritores confirmarán cómo la colmena legendaria de Heródoto, convertida en y asimilada a un cofre ${ }^{80}(\lambda \alpha ́ \varrho v \alpha \xi)$, se hizo real y constatable en Olimpia. Plutarco nos dice que, debido a la colmena que lo salvó, Cípselo mandó a construir en Delfos un edificio, creyendo que los dioses le habían hecho parar el

75 Véanse Roux 1963; Oost 1972, p. 17: "The child was named Cypselus, almost certainly not in connection with a Greek word meaning 'jar', or 'chest', (probably a late folk etymology), but perhaps with reference to the Greek word for Sandpiper". Y también nota 33: "I must confess to some reservations about a man named 'Eagle' giving the name 'Sandpiper' (a kind of swallow) to his son; but some totemistic significance, or similar idea, if the name did actually mean 'Sandpiper', and if his parents were consciously thinking of that meaning, may well escape us".

${ }^{76}$ Homero conoció al menos dos casos de mujeres onomásticamente vinculadas a aves. Véase Il., 9.561-564, en donde el poeta nos habla de Cleopatra, la esposa de Meleagro, a quien su padre y su madre llamaban Alcíone, en honor al pájaro Alción. También véase Il., 14.289291, en donde se nos habla del ave a la que los dioses llaman Calcis y los hombres Cymindis.

${ }^{77}$ Para la cera de las alas de Dédalo véase Diod. Sic., 4.77.8, aunque ahí utiliza el sustantivo

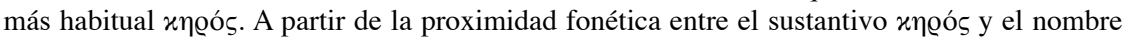
"Ixa@os, algunos escritores como Luciano utilizaron el recurso paronomástico, véanse Icar., 3.5, Gall., 23, e Im., 21.

${ }^{78}$ Este sentido se corrobora, por ejemplo, en el fragmento XVII de las Póleis del comedió-

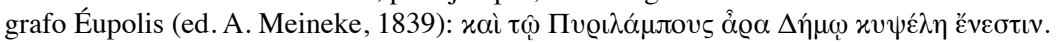

${ }^{79}$ Meineke 1839, p. 515.

${ }^{80} \mathrm{El}$ motivo del cofre es característico del mito de Perseo; véase el drama satírico de Esqui-

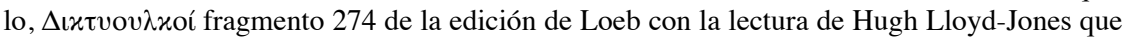
restituye un $\lambda$ á $\varrho v \alpha x \iota$ (fr. 46a Radt); Simónides (fr. 543.1 Page) en donde se emplea también un

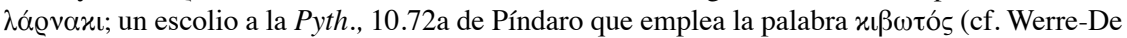
Haas 1961, pp. 5-6, en donde hay una recopilación de las fuentes que hablan sobre la infancia

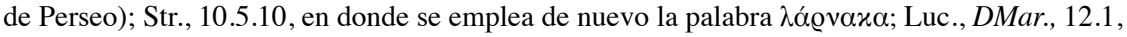

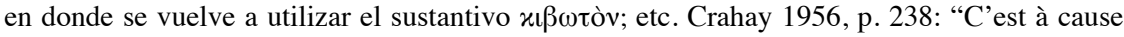
de cette étymologie que la biographie légendaire de Cypsélos a choisi pour modèle, parmi les defférentes versions de la légende du Conquérant, celle de Persée où intervient un coffre". 
llanto cuando estaba escondido en la colmena a fin de que los Baquíadas no lo encontraran.$^{81}$ Podría haber aquí un indicio de cómo el tirano legitimó su poder mediante el refuerzo de su propia leyenda. Dion Crisóstomo dice haber visto en el templo de Hera en Olimpia un memorial del rapto de Helena representado en un cofre de madera ( $\dot{\varepsilon} v \tau \hat{\eta} \xi \xi \nu \lambda i v \eta \eta$ sido ofrendado a Zeus por Cípselo. ${ }^{82}$ Finalmente, Pausanias afirma haber observado también en Olimpia el cofre de cedro ( $\lambda \alpha$ $\varrho v \alpha \xi \delta$ $\delta \grave{~ x \varepsilon ́ \delta \varrho o v) ~ e n ~ q u e ~}$ la madre de Cípselo lo ocultó. Y explica que dicho cofre fue ofrendado a Olimpia por los descendientes de Cípselo. ${ }^{83}$ Estos testimonios evidencian claramente el papel de la etimologización en la conformación legendaria y mítica de la historia. Heródoto ocupa aquel puesto intermedio en el que la leyenda se está haciendo "historia".

\section{CONCLUSIONES}

En este estudio hemos tratado de demostrar cómo los nombres propios a lo largo de las Historias de Heródoto tienen una función narrativa importante y están íntimamente vinculados al método de exposición histórica del autor. Los significados de los nombres funcionan como microrrelatos paralelos al episodio en que se insertan y, a veces, contribuyen al diseño, la configuración y la estructura de un relato general más amplio, confluyendo así el microrrelato inscrito en el nombre con el "macrorrelato" en el que el personaje actúa ${ }^{84}$ Los nombres que hemos analizado aquí, el del bastardo tartamudo que se convierte en rey, el del señor Carnero, el del rey que es, primero, plegaria y luego maldición de su pueblo y, finalmente, el del vencejo escondido en su colmena son, todos ellos, significativos para el desenvolvimiento narrativo de las Historias y demuestran cómo a veces el nombre determina la leyenda, pero otras la leyenda forma el nombre. Los nombres son cápsu-

${ }^{81}$ Conv. sept. sap., $163 \mathrm{f}$.

82 Or., 11.45.

83 5.17.5. Véase Stuart Jones 1894.

${ }^{84}$ Uno de los dictaminadores anónimos que evaluaron este trabajo me sugirió señalar qué uso específico tiene en la historiografía la cuestión del microrrelato relacionado con los nombres y me llamó la atención sobre un pasaje en la obra de Polibio en el que se desarrolla un diálogo humorístico entre Filipo V y un político etolio de nombre "Feneas" (literalmente "el que trae la luz" y que paradójicamente es medio ciego), que le sirve al historiador "para presagiar el desenlace de un fatal error político posterior" (véase Moreno Leoni 2014, pp. 157-172). Me parece un tema muy importante y sugerente que, desafortunadamente, no puedo enfocar aquí, pero que, en todo caso, apunta a que el uso de los nomina loquentia como microrrelatos fue un procedimiento desarrollado por otros historiadores antiguos. Cabría investigar entonces en qué medida la herencia herodotea pesa sobre ellos en este aspecto y cuáles fueron los propósitos y objetivos específicos de cada uno al emplearlos. 
las que el historiador puede abrir y esta apertura es la que posibilita el despliegue del discurso literario de la historia. Además, el historiador también puede devenir onomaturgo, creador e inventor de nombres que se amoldan a los acontecimientos de su narración.

En el primer caso, el del nombre del rey de Cirene, Bato, personaje central dentro del $\lambda$ ó $\gamma_{0} \lambda_{\iota} \beta v x o ́ s$, se puso en evidencia cómo se trata de una denominación que es explicada por el historiador a partir de la ambigüedad de su significado: rey en libio, tartamudo en griego. La participación del oráculo délfico en el relato resulta fundamental, pues el vaticinio profético facilita el despliegue de la ambigüedad en la interpretación del sentido del nombre. Y tal ambigüedad, que articula el episodio completo, sólo puede resolverse cabalmente en Libia, aquel mundo inhóspito en donde los valores onomásticos griegos llegan a tergiversarse a tal grado que un tartamudo puede convertirse en rey. El significado ambiguo del nombre del primer rey de Cirene no sólo organiza la información de que dispone el historiador, sino que además contribuye a la interpretación de los datos y a su organización artística y literaria.

En el segundo ejemplo, el del nombre de Crío el egineta, personaje que actúa dentro del relato sobre la historia de Esparta, la motivación zoológica de su significado ("el carnero") le permite a Heródoto reportar la frase ingeniosa que el rey espartano, Cleómenes, le dirigió: "cubre tus cuernos de bronce", locución casi oracular que requiere, para su interpretación y comprensión, el ejercicio de etimologizar el nombre del personaje. Se trata de un caso paradigmático de etimología poética, pues el nombre mismo de Crío y la figura del carnero evocan una serie de referencias del imaginario literario y cultural griego que se hallan implícitas en la apelación (los titanes, la figura de Hermes, el episodio mitológico del vellocino de oro y la conformación de la lira). Por otra parte, el juego etimológico no articula, como en el caso anterior, los acontecimientos del episodio y la información recogida por el historiador, sino que más bien revela una cualidad del personaje que lo pronuncia, a saber, el estilo ingenioso de su lengua que no es únicamente un elemento humorístico para embellecer el relato, sino que manifiesta la convicción de que en ciertas circunstancias el conocimiento del nombre verdadero y su pronunciación pueden acarrear consecuencias ominosas. El destino trágico y suicida de Cleómenes en las Historias, cuyo nombre expresa las nociones de fama y gloria ( $x \lambda \hat{\varepsilon} о \varsigma)$, ímpetu y fuerza ( $\mu \varepsilon^{-}$ vos), está íntimamente ligado a los modos ingeniosos e irreverentes de su jerga lingüística.

En el tercer caso, el del nombre de Demarato, el rey cuyas acciones se desarrollan también en el libro sobre la historia de Esparta y cuyo protagonismo resulta fundamental para describir las formas en que un mismo personaje puede encarnar papeles contrarios y determinantes para los acon- 
tecimientos históricos, se pudo constatar cómo su significado de nuevo vincula y estructura los episodios en los que participa. Debido a las ambigüedades semánticas del sustantivo à @́, que significa tanto "plegaria" como "ruina" y "maldición", la vida de Demarato, plegaria y luego ruina del pueblo espartano, personifica la conversión semántica inscrita en la ambigüedad de su nombre.

Finalmente, el último análisis, el del nombre de Cípselo, personaje central del relato herodoteo sobre la ciudad de Corinto y la tiranía que ahí se impuso, no sólo evidencia cómo en las Historias la estructuración de ciertos episodios y la interpretación de los mismos se basa en la etimologización de un nombre (el bebé que recibió su apelativo por haber sido escondido en una colmena, pero que también, hijo de un águila, prolonga su linaje ornitológico llamándose "el vencejo"), sino que, además, revela los vínculos profundos entre la tiranía de esta ciudad griega y el clero de Delfos.

Cuatro personajes, cuatro ciudades (Cirene, Egina, Esparta y Corinto), cuatro nombres que prueban cómo el discurso histórico de Heródoto y el trabajo de interpretación onomástica y creación onomatúrgica son elementos solidarios que se acoplan en ese admirable monumento artístico que son las Historias.

\section{BIBLIOGRAFÍA}

\section{Fuentes antiguas}

Anthologia Graeca, Band IV: Buch XII-XVI. Griechish-Deutsch, ed. Hermann Beckby, Münich, Heimeran, 1968.

Cicero's Topica, Intr., Transl. and Comm. Tobias Reinhardt, Oxford, Oxford University Press, 2003.

Erodoto, Le Storie. Libro V. La Rivolta della Ionia, ed. Giuseppe Nenci, Florencia, Fondazione Lorenzo Valla, 1994.

Fragmenta Poetarum Comoediae Antiquae, t. II.1, ed. August Meineke, Berlin, Walter de Gruyter, 1839.

Hérodote, Histoires. Livre V, Phillipe-Ernest Legrand, Paris, Les Belles Lettres, 1946.

Hérodote, Histoires. Livre VII, Paris, Les Belles Lettres, 1951.

Hérodote, Histoires Livre IV, Paris, Les Belles Lettres, 1960.

Heródoto, Historia . Libros V-VI, trad. Carlos Schrader, Madrid, Gredos, 1981.

Hesiod, Theogony, ed. Martin L. West, Oxford, Clarendon Press, 1966.

Hesychil AleXandrini Lexicon, vols. 1-2, ed. Kurt Latte, Copenhagen, Munksgaard, $1966^{2}$.

PINDARI Carmina cum fragmentis, 5th ed., ed. Herwig Maehler (post B. Snell), Leipzig, Teubner, 1971. 
Quintilian, Institutio Oratoria: Books I-III, ed. Harold E. Butler, Cambridge/London, Harvard University Press, 1920.

Scholia in Theocritum vetera, ed. Carl Wendel, Stuttgart, Teubner, 1966.

Thesaurus Linguae Graecae. A Digital Library of Greek Literature, http://stephanus. tlg.uci.edu/ (27/02/2020).

\section{Fuentes modernas}

Antonelli, Luca, "Cadmo ed Eracle al cospetto di Apollo. Echi di propaganda intorno a Delfi arcaica”, Hesperìa 4. Studi sulla grecità di occidente, ed. Lorenzo Braccesi, Roma, “L'Herma” di Bretschneider, 1994, pp. 13-48.

Asheri, David, Alan Lloyd and Aldo Corcella, A Commentary on Herodotus Books I-IV, Oxford, Oxford University Press, 2007.

Barthes, Roland, "Proust et les noms", en Le degré zéro de l'écriture. Suivi des Nouveaux essais critiques, Paris, Seuil, 1972, pp. 118-130.

Berruecos Frank, Bernardo \& Stefania Giombini (eds.), Alberto Bernabé Pajares et al. Parmenide: tra lingüística, letteratura e filosofía, Baden, Academia Verlag, 2019.

Boedeker, Deborah, "The two Faces of Demaratus", Arethusa, 20, 1987, pp. 185201.

Boer, Willem Den, “The Delphic oracle concerning Cypselus", Mnemosyne, 10, 1957, p. 339.

Calame, Claude, Le récit en Grèce ancienne, Paris, Belin, 2000.

Campos Daroca, Javier, Experiencias del lenguaje en las "Historias de Heródoto", Almería, Instituto de Estudios Almerienses, 1992.

Carrington, A. G., "Ram, Tortoise and Lyre in Greek Epigram", Mnemosyne, 14/1, 1961, p. 22.

Chantraine, Pierre, Dictionnaire étymologique de la langue grecque: histoire des mots, Paris, Klincksieck, 1980.

CRAHAY, Roland, La Littérature Oraculaire chez Hérodote, Paris, Les Belles Lettres, 1956.

Delcourt, Marie, Stérilités Mystérieuses et Naissances Maléfiques dans l'Antiquité Classique, Paris, Les Belles Lettres, 1986.

Dewald, Carolyn, "Humour and Danger in Herodotus", en Carolyn Dewald and John Marincola (eds.), The Cambridge Companion to Herodotus, Cambridge, Cambridge University Press, 2006, pp. 145-164.

DiEls, Hermann, “Die Anfänge der Philologie bei den Griechen”, Neue Jahrbuch für Philologie, 25, 1910, pp. 1-25.

Farnell, Lewis Richard, The Cults of the Greek States, vol. V, Chicago, Aegean Press, 1971.

FRISK, Hjalmar, Griechisches Etymologisches Wörterbuch, Heidelberg, Carl Winter Universitätsverlag, 1973.

GraY, Vivienne J., "Herodotus and Images of Tyrany: The Tyrants of Corinth", The American Journal of Philology, 117/3, 1996, pp. 361-389. 
Hainsworth, Bryan, The Iliad: A Commentary. Volume III: Books 9-12, Cambridge, Cambridge University Press, 1993.

HART, John, Herodotus and Greek History, London, Croom Helm, 1982.

Holwerda, Douwe, Prolegomena de comoedia. Scholia in Acharnenses, Equites, Nubes, Groningen, Bouma, 1977.

How, W. W. and J. Wells, A Commentary on Herodotus, vol. II, Oxford, Oxford University Press, 1968.

Immerwahr, Henry H., Form and Thought in Herodotus, Chapel Hill, The American Philological Association, 1966.

JAKOBSOn, Roman, "Linguistics and Poetics", in Krystyna Pomorska and Stephen Rudy (eds.), Language in Literature, Cambridge/London, Harvard University Press, 1987, cap. 6, pp. 62-94.

Johnson, David M., "Herodotus' Storytelling Speeches: Socles (5.92) and Leotychides (6.86)", The Classical Journal, 97/1, 2001, pp. 1-26.

LAmbert, Michael, "Ancient Greek and Zulu Sacrificial Ritual: A Comparative Analysis", Numen, 40/3, 1993, pp. 293-318.

LARSON, Stephanie, “Kandaules' wife, Masistes' wife: Herodotus narrative strategy in suppressing Names of women", The Classical Journal, 101/3, 2006, pp. 225-244.

LATEINER, Donald, "Signifying Names and Other Ominous Accidental Utterances in Classical Historiography", Greek, Roman and Byzantine Studies, 45, 2005, pp. 35-57.

Liddell, Henry G., Robert ScotT and Henry Stuart Jones, Greek-English Lexicon, Oxford, Clarendon Press, 1996.

Louden, Bruce, "Categories of Homeric Wordplay", Transactions of the American Philological Association, 125, 1995, pp. 27-46.

Masson, Olivier, "Le nom de Battos, fondateur de Cyrène, et un groupe de mots grecs apparentés", Glotta, 54, 1976, pp. 84-98.

McCartney, Eugene S., "Anthologia Palatina XIV. 30”, The Classical Review, 3637/8, 1922, p. 165.

Moles, John, "'Saving' Greece from the 'ignominy' of Tyrany? The 'famous' and 'wonderful' speech of Socles (5.92)", in Elizabeth Irwin and Emily Greenwood (eds.), Reading Herodotus. A study of the logoi in book 5 of Herodotus' Histories, 2007, pp. 245-268.

Molyneux, John H., Simonides. A Historical Study, Wauconda, Bolchazy-Carducci Publishers, 1992.

Moreno Leoni, Álvaro, "The failure of the Aetolian deditio as a didactic cultural clash in the Histories of Polybius", Histos, 8, 2014, pp. 146-179.

Nagy, Gregory, The Best of the Achaeans. Concepts of the Hero in Archaic Greek Poetry, Baltimore, The Johns Hopkins University Press, 1979.

Oost, Stewart Irvin, "Cypselus the Bacchiad", Classical Philology, 67/1, 1972, pp. 10-30.

Peradotto, John, Man in the Middle Voice: Name and Narration in the Odyssey, Princeton, Princeton University Press, 1990.

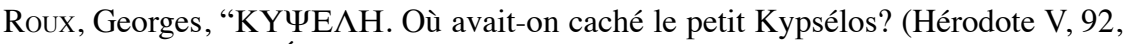
E)", Revue des Études Anciennes, 65/3-4, 1963, pp. 279-289. 
Stuart Jones, Henry, “The Chest of Kypselos", The Journal of Hellenic Studies, 14, 1894, pp. 30-80.

Todorov, Tzvetan, "Meaning in Literature: A survey", Poetics, 1/1, 1971, pp. 8-15. Tsitsibakou-Vasalos, Evanthia, Ancient Poetic Etymology. The Pelopids: Fathers and Sons, Stuttgart, Franz Steiner Verlag, 2007.

Vernant, Jean Pierre et Pierre Vidal-Naquet, Mythe et tragédie en Grèce ancienne, Paris, La Découverte, $1995^{2}$.

Werre-De Hads, Margaretha, Aeschylus' Dictyulci. An attempt at reconstruction of a satyric drama, Leiden, Brill, 1961.

Woodbury, Leonard, "Parmenides on names", Harvard Studies in Classical Philology, 63, 1958, pp. 145-160.

$$
* * *
$$

Bernardo Berruecos Frank es doctor en Filología griega y en Filosofía, especialidad en Filosofía antigua, por la Universidad de Barcelona y la Aix Marseille Université de Francia. Es investigador titular de tiempo completo del Centro de Estudios Clásicos del Instituto de Investigaciones Filológicas, de la Universidad Nacional Autónoma de México. Ha centrado su investigación en los procesos de transmisión textual de la poesía lírica y en la tradición filosófica griega, con especial énfasis en el periodo presocrático. Entre sus publicaciones, destacan el volumen Poesía arcaica griega. Tomo I. Poesía parenética de la Bibliotheca Scriptorum Graecorum et Romanorum Mexicana (2018), diversos artículos en revistas arbitradas, entre los cuales están "Bene rotunda et globosa veritas. Epítetos de la verdad en Parmenides DK28 B1.29”, Archai: The Origins of Western Thought, 26, 2019, y diversos capítulos en libros internacionales como "Hérodote, présocratique?", en X. Riu \& M. Reig (eds.), Drama, Philosophy, Politics in Ancient Greece, Universidad de Barcelona (2014), y, en coautoría con E. Hülsz Piccone, "Parménides B1.3: Una nueva enmienda", en M. Pulpito \& P. Spangenberg (eds.), ódò̀ vô̄odı. Ways to Think. Essays in Honour of Néstor-Luis Cordero, Diogene Multimedia, Axiothéa (2018). Finalmente, fue coeditor del libro Alberto Bernabé et al., Parménide: tra linguística, letteratura e filosofía, Academia Verlag-Nomos Verlagsgesellschaft (2019). 